\title{
Universitário, redação e SPI ${ }^{1}$
}

\author{
Eliana de Azevedo Arouca \\ $U M C$ e $U B C$
}

\begin{abstract}
Resumo
Como a comunicação escrita de estudantes de Comunicação tem merecido pouca atenção dos pesquisadores, objetivou-se testar a eficiência de um material programado com base no Sistema Personalizado de Ensino sobre linguagem escrita para universitários do segundo ano de Comunicação Social, enfatizando o ensinoaprendizagem do texto dissertativo acadêmico. Os resultados evidenciaram progresso qualitativo para a maioria dos sujeitos, o que permite inferir que a estrutura do material aplicado foi favorável aos sujeitos, entretanto o tempo de aplicação (10 dias) revelou-se insuficiente para uma mudança na utilização de técnicas aplicáveis a redações dissertativas e para que fossem supridas deficiências dos graus antecessores. Sugeremse cursos de remediação de leitura e de escrita.
\end{abstract}

Palavras-chave: dissertação, material programado, comunicação

\section{Students af university, disserta tive writing and SPI}

\begin{abstract}
Summary
Writing skills of Communication students have had little attention from researchers. It has been aimed to test efficiency of a programed material based on Teaching Personalized System about written language for university students at the Second Grade in Social Communication, enphasizing the text teaching - leaming in academic leveI. The results showed quality improvement for most individuals. This fact made us conclude that the sctructure of the applied material was positive to the individuals, but the time (10 days) was not enough for a change in the use of techniques in dissertative writings and for elimination of difficulties in the preceeding levels. Remedy courses on reading and writing are suggested.
\end{abstract}

Key-words: dissertation, programed material, communications.

A Autora procurou testar a eficiência de um material programado para a aprendizagem do texto dissertativo, porque percebe que o aluno universitário, embora sendo uma pessoa vivente e atuante e com condições de emitir opiniões e pontos de vista a respeito dos fatos do mundo, muitas vezes, não consegue expressar por escrito o que pensa, porque não conhece ou não lhe foram ensinadas técnicas de como esquematizar e produzir texto escrito.

Segundo Santos (1987), no Brasil, os professores, principalmente do Curso de Letras, não estão preparados para trabalhar com a criatividade; assim, privilegiam a forma e não o conteúdo, o que leva o aluno a escrever pouco, para cometer menos erros. Por vezes, o aluno apresenta grande receio de expor-se e receber nota ou críticas em suas redações. Chegam, portanto, à Universidade sem terem adquirido o hábito da escrita. Esses fatos acarretam constante e generalizada interrogação sobre a eficiência, ou mesmo a continuidade do ensino de Português nas Universidades; é preciso buscar soluções que integrem teoria e prática, de modo a não só suprir deficiências como também possibilitar a aquisição de mecanismos que possibilitem o ensino-aprendizagem da escrita, de maneira a melhorar a qualidade da expressão das idéias.

Trabalhos foram realizados para avaliar o comportamento de vestibulandos e apontaram para algumas dificuldades que não podem ser ignoradas. Dentre estes, vale lembrar que, no Brasil, realizou-se uma pesquisa com candidatos ao vestibular da área de Ciências Biomédicas, no ano de

\footnotetext{
${ }^{1}$ Parte da Introdução da Dissertação de Mestrado Validação de um Material de Linguagem Escrita Aplicado a Universitário, defendida pela autora na PUCCAMP, sob a orientação de G. P. Witter, contando em parte com bolsa do CNPq.
} 
1976. Carone (1976) analisou 693 redações em termos de identificação de desvios do sistema lingüístico. Duas conclusões são destacadas pela autora: a) o vazio das idéias, atribuído à falta de informações e b) dificuldade na organização de idéias, atribuída à falta de articulação verbal adequada e à limitação e inadequação de vocabulário utilizado. Situação, portanto, bastante reveladora da falta de leitura (e oportunidade de debate e crítica), bem como da ausência do hábito de escrever.

Realizando um trabalho semelhante, Rocco (1981) fez uma análise das redações dos vestibulandos da FUVEST e observou que os textos apresentavam as seguintes deficiências lingüísticas: falta de coesão; incoerência; ruptura de nexos lógicos; uso excessivo de clichês; falta de originalidade e de criatividade.

A grande realidade é que atualmente há facilidade de ingresso no ensino superior, mesmo para estudantes que apresentam deficiências de habilidades consideradas básicas e muitos estudos foram feitos no sentido de detectar as causas desse fato. ${ }^{2}$ Há de se buscarem alternativas que acabem sendo encaradas como instrumentos úteis, que permitam ao aluno a construção de textos próprios, corretos e adequados, tomando o ato de escrever uma atividade normal, habitual e prazerosa e não mais aquele repúdio e temor ante a folha de papel em branco fato que é constatado quando da entrada do aluno na Universidade, decorrente, pelo menos em parte, de lacunas grandes e graves na aprendizagem verbal.

"A peculiaridade da escrita decorre da utilização da grafia e do espaço em branco da página... existe necessariamente um lapso espacial e temporal entre o momento da enunciação e $o$ da recepção" (Sato 1989:56). O professor deve, então, de acordo com Barras (1995), não somente ensinar os alunos a usar as palavras, mas também encorajá-los a empregar efetivamente o uso da língua. Os alunos precisam ser estimulados por meio de críticas construtivas aliadas ao ensino de técnicas que prevejam a aprendizagem gradual de construção e produção próprias de texto.

Conforme Bright, (1993) e Barras (1995), a ênfase no ensino-aprendizagem da escrita deve ser maior no processo, entretanto sem se descuidar do produto. Deve-se considerar a necessidade de se desenvolver o hábito da escrita como rotina, facilitando ao aluno as atividades de pensar, planejar, escrever e revisar.

Um dos discursos escritos mais freqüentes no mundo universitário é a dissertação, aqui destacada para estudo.

\section{Aprendizagem de discurso e SPI}

A aprendizagem de técnicas específicas para se compor o texto é fundamental e esse aprendizado pode ocorrer por meio de exercícios elaborados para aulas programadas que propiciem o domínio das estruturas lingüísticas e a conseqüente fluência da expressão no uso da língua.

Muitas são as possibilidades disponíveis para o ensino-aprendizagem do discurso, cabendo ao docente optar pela que considera possivelmente mais eficiente na realidade em que atua. No presente estudo, a opção foi pela aplicação de algumas características do Sistema Personalizado de Instrução (SPI) ou Curso Programado ou Método Keller (1968) em um material programado para ensino-aprendizagem de linguagem escrita tais como: conteúdo programático ministrado via tarefas dirigidas, seqüenciais, logicamente elaboradas, em grau crescente de dificuldade, segundo uma

\footnotetext{
${ }^{2}$ Lembre-se Rocco (1981); Pereira (1983); Marini (1986); Duran (1981); Santos (1989) entre outros.
} 
hierarquia comportamental definida do simples para o complexo; do conhecido para o desconhecido, respeitando-se o nível de complexidade da matéria e o nível de conhecimentos dos alunos.

O Método Keller ou Sistema Personalizado de Ensino ou Curso Programado foi introduzido pelo psicólogo Fred Keller, em 1963, na Universidade de Colúmbia e, no Brasil, em 1964, na Universidade de Brasília. Também é conhecido como Curso Programado Individualizado (CPI).

Muitas pesquisas foram estimuladas pela organização do Centro de Ensino Personalizado, em Washington, Universidade de Georgetown com a utilização da moldura teórica do SPI, especialmente no ensino superior; inclusive comparando-se esse sistema de ensino com métodos tradicionais com aulas expositivas. Há também pesquisas de professores-pesquisadores, visando a testar as possibilidades do SPI ao ensino de suas respectivas disciplinas.

Por exemplo, Witter \& Rosamilha (1969) fizeram um estudo comparativo desta tecnologia com o ensino tradicional. Witter \& Witter (1973) apresentaram no VI Simpósio Nacional dos Professores Universitários de História "Um curso Programado de História” que objetivou considerar a validade desta técnica, num programa para o ensino do Período Republicano, da História do Brasil. Ou ainda a Tese de Doutorado de Bastos (1995), que criou um Programa de Redação com base no Sistema Personalizado de Instrução. Mostrou ser o SPI uma tecnologia eficiente no ensino de atividades lingüísticas complexas como é o caso da elaboração de monografia de final de curso.

De modo geral, os pesquisadores que se têm dedicado ao estudo do SPI têm concluído pela sua superioridade em relação a outros cursos convencionais (Marini, 1980).

Os princípios de aprendizagem adotados no SPI baseiam-se no Condicionamento Operante, cujo mecanismo foi desvendado especialmente pelo psicólogo norte-americano Skinner.

Os reforços positivos utilizados no SPI referem-se à satisfação de necessidade de caráter social, tais como: aprovação por unidades; rápida progressão no curso; elogio do professor; admiração dos colegas; satisfação pelo contato e domínio do conteúdo de estudo. "Deve-se proporcionar ao estudante universitário uma estratégia de instrução individualizada que, de alguma maneira, facilite-lhe a rápida compreensão dos materiais que lê e, em conseqüência, permita-lhe certo domínio do assunto do qual se ocupa” (Chacón, 1989:107).

O SPI é estruturado de forma a eliminar os reforçadores negativos, como ameaças do professor ou perigo de reprovação. As avaliações podem realizar-se por meio de exames, entrevistas ou de qualquer outro meio que o professor considere conveniente de acordo com a situação técnicoadministrativa da instituição (Chacón, 1989).

Dessa forma, eventuais efeitos negativos são contornados no sistema de avaliação do SPI, por meio de um reforço contínuo que objetiva uma regularidade de ocorrências positivas. Esse reforço ocorre na forma de elogios e aceitações das respostas dos Ss que têm seu comportamento modelado pelo texto e pelo professor, de modo que possam responder com grande probabilidade de êxito. "Deve-se ter claro que as avaliações são para chegar à excelência, nunca para reprovar" (Chacón, 1989:114).

Um outro elemento que pode ser manipulado no processo de condicionamento operante é o estímulo que antecede o desempenho. Se o estímulo for adequado e eficiente, - pode ser manipulado para que ocorra a resposta especificada -, se a organização das condições para que ocorram determinadas respostas for adequada, se o controle do ambiente for adequado, haverá respostas que 
se orientarão para os objetivos especificados do curso programado. De acordo com Chacón (1989), no caso de aprendizagem na área de língua, um estímulo, por meio de um material programado, pode oferecer ao estudante oportunidades reais para que ponha em prática processos cognitivos, tais como analisar, sintetizar, comparar e generalizar e, desta forma, ajudá-lo no uso racional de variadas fontes de informação.

O texto-estímulo pode ser o ponto de apoio para a produção. Nada se cria do nada. De acordo com Unrau (1995), discussões e troca de idéias entre a classe e o professor é atividade produtiva para que o aluno teste sua própria argumentação.

De acordo com Bright (1993), conhecer as dificuldades que os alunos possuem para escrever e como se vêem a si mesmos como escritores pode ser decisivo para o ensino-aprendizagem da escrita. O professor, portanto, deve propiciar que os alunos escrevam, usando a função expressiva da linguagem, dando-lhes liberdade de expressão.

Dessa forma, de acordo com Hudson (1988), quanto maior o controle que o indivíduo possui de si mesmo, por meio da elaboração de sua escrita, maior a compreensão sobre seu próprio trabalho.

Com esses requisitos e técnicas adequadas dentro da concepção ensino-ciência, conforme Witter (1975), poder-se-ão desenvolver as habilidades necessárias para a expressão escrita.

Keller $(1970,1983)$ usa a palavra instrução num sentido amplo. Entende por instrução o estabelecimento de contingências para o fornecimento de conhecimento ou para o desenvolvimento de uma habilidade. Para ele, ensino quer dizer aplicação dos princípios da aprendizagem.

O Método Keller possui algumas linhas básicas, consideradas válidas até hoje. São as seguintes:

1. Característica "vá na própria velocidade” , para um estudante realizar o curso a uma velocidade compatível com a sua capacidade e com outras demandas sobre o seu tempo.

2. Cada unidade deve corresponder a objetivos bem precisos e o aluno só passa para a unidade subseqüente após ter alcançado o critério de desempenho correspondente aos objetivos.

3. O uso de palestras e demonstrações como veículos de motivação, ao invés de fontes de informações.

4. Ênfase na comunicação escrita estabelecida entre alunos e professores.

5. Uso de monitores que possibilitem a aplicação de testes repetidos, avaliação imediata, ensino particular quase inevitável e marcado realce nos aspectos sociais e pessoais do processo educacional.

6. Uso dos princípios da aprendizagem, com ênfase em: reforçamento positivo, modelagem, modelação, discriminação e generalização.

São essas as diretrizes que têm orientado os esforços de pesquisadores interessados nesse sistema de ensino, com vista a contribuir para o aperfeiçoamento de detalhes e variações metodo lógicas do mesmo, sugerindo formas alternativas dentro desse quadro. "O plano Keller serviu de base para desenhar uma estratégia de instrução que facilita o estudante resolver seus problemas de compreensão...ainda mais numa sociedade e no mundo mutável onde o exerCÍcio da linguagem e de seu domínio cultural propicia a tomada de decisões..." (Chacón, 1989:119).

O Sistema Personalizado de Instrução é uma forma de ensino que apresenta vantagens e 
limitações, principalmente quando o sistema educacional restringe a aplicação integral de todas as suas características. O método Keller foi idealizado inicialmente para uma aplicação no campo científico, mas há trabalhos que extrapolaram esse uso com sucesso, em várias áreas. Entre eles, Kock (1997) que avaliou uma proposta para o ensino de conceitos e aplicações da Física para universitários do primeiro ano, concluindo que a estratégia de ensino utilizada com características do SPI, de maneira geral, pareceu atender às expectativas, no sentido de contribuir para a formação do engenheiro, embora fosse ressaltada a necessidade de monitores e de instrutores, além da figura do professor, para maior atenção ao aluno durante o processo ensino-aprendizagem.

Segundo Keller (1968), as características básicas do Curso Programado podem ser resumidas nos seguintes itens: a) apresentação de matéria em quantidades reduzidas e em graus crescentes de dificuldades, atendendo-se uma hierarquia definida em termos de comportamento; b) as contingências reforçadoras devem ser cuidadosamente planejadas; c) ao terminar um curso, todos os alunos devem apresentar os comportamentos finais que foram previamente definidos; d) o desempenho final da classe, em sua quase totalidade, é de alto nível, e quase todos os alunos alcançam a nota máxima. Em outras palavras: "Os cursos programados apresentam as mesmas características gerais da instrução programada, uma vez que os mesmos princípios de aprendizagem são usados de modo a garantir a eficiência do ensino: a matéria é apresentada em pequenas doses, em graus crescentes de dificuldades e segundo uma hierarquia comportamentalmente definida: são feitas revisões e avaliações freqüentes e os reforços são devidamente programados de modo a garantir que todos os alunos, em seu próprio ritmo alcancem o objetivo pré-estabelecido, com nível de proficiência semelhante” (Witter \& Witter 1973:34).

Dessa forma, as dificuldades devem ser propostas de forma a serem resolvidas; o aluno deve caminhar para o êxito. Se houver progressão com sucesso, o aluno ficará mais motivado. Entretanto, o sucesso do material programado também está na dependência do próprio aluno, “ $a$ programação não contém um feitiço motivador que ligue o aluno, magicamente, à tarefa da aprendizagem" (Schiefele 1964:112).

Em termos de Brasil, é evidente que se fazem necessárias algumas adaptações nas proposições de Keller, face às exigências burocráticas. Uma vez que o ritmo individual varia dentro de certa amplitude, é, conforme Witter (1973), possível prever-se, após algumas aplicações de um dado conteúdo, com esta tecnologia, qual será a média de tempo requerida e qual a sua amplitude possível. "É evidente que são imprescindíveis algumas mudanças na estrutura curricular $e$ instrucional, mudanças que obedeçam à necessidade de um compromisso adquirido com o país, com a educação e com os indivíduos para guiá-Ios até o êxito” (Chacón, 1989:120).

Considerando variáveis dentro de um tempo para as atividades programadas como conteúdo, dificuldade no conteúdo, nível inicial do conhecimento do aluno, pode ocorrer que um aluno termine antes ou demore mais no programa do que foi previsto. Daí, a necessidade de adaptações ao sistema brasileiro de ensino, em que o professor precisa entregar notas em prazos préestabelecidos. Por isso, o professor deve estabelecer limites máximos para o término do programa.

Além disso, alguns pressupostos são levados em conta neste programa de ensino como não ensinar pelo erro; proporcionar acertos para que o aluno adquira segurança e prazer no ato de escrever; não permitir descontextualização e sempre solicitar produção do aluno, mantendo interação constante do aluno com textos e docente, em processo de negociação de significados.

Com este procedimento, "não é relevante que o professor tenha facilidade para falar e dar 
brilhantes aulas expositivas. Ao contrário, essa característica é de pouca importância. O que realmente importa é que ele domine bem a matéria, estando perfeitamente apto a resolver as eventuais dúvidas que possam surgir.” (Witter, 1973:102).

O professor terá condições de verificar objetivamente o progresso de seus alunos, o que certamente lhe trará alguns reforçadores que há muito deixou de ter em sua profissão e sentirá uma grande satisfação em participar de um processo que aproxima tanto quem escreve quanto quem lê. Poderá sentir o que Keller (1967: 144) denominou "uma nova dignidade em sua profissão"..

Entretanto, nenhum programa pode substituir a figura imprescindível do professor em sala de aula e esse fato encontra respaldo nas palavras de Witter (1973: 103) "O professor é o principal responsável pela programação, aplicação, avaliação e reprogramação do sistema de ensino, isto é, por todas as suas fases ".

O Sistema Personalizado de Instrução - SPI - é uma tecnologia de ensino que objetiva oferecer ao aprendiz atendimento pessoal e tutorial, com programação orientada para o êxito. "Um dos princípios básicos do ensino-programado é a constante confirmação do êxito pela solução certa dos diversos itens da aprendizagem" (Schiefele 1964: 111).

Apresenta três fases: programação, aplicação e análise dos resultados. "Trata-se de uma tecnologia de ensino que se baseia em dados obtidos por psicólogos em laboratórios e salas de aula: enquadra-se na concepção de ensino-ciência, porque precisa ser planejada a partir do conhecimento e mediante as possibilidades reais do aprendiz, bem como das circunstâncias de ensino" (Bastos 1995: 20).

Adequando-se à realidade brasileira em que há falta de apoio dos administradores para trabalhos de pesquisa, o próprio professor pode exercer as três funções: de programador, de executor e de monitor dos alunos, não individualmente e de avaliador dos resultados obtidos, para verificar o proveito real da estratégia utilizada, bem como as deficiências havidas.

A possibilidade do texto-estímulo, a aprovação do professor, a oportunidade de o aluno perguntar o que não entendeu, fazer e refazer seus textos, sem punição, fortalecem comportamentos. Isto implica aumento de chances para que esses comportamentos positivos tomem a ocorrer no futuro, ou seja, o aluno passe realmente a gostar de escrever. Desta forma, espera-se que o escrever passe a ser uma resposta auto-reforçadora.

Esses reforços positivos poderão ser liberados durante avaliações sugeridas em cada unidade do programa. São aprovações por itens; há uma rápida progressão; prevê-se o elogio do professor, uma vez que cada exercício é organizado prevendo-se o acerto e o próximo é estruturado, começando por uma revisão do último conteúdo estudado. Esses reforços trazem como conseqüência a satisfação pelo contato e domínio do estudo reforço esse denominado por alguns psicólogos de resposta reforçadora (Keller, 1970).

Como exemplo do uso do Método Keller, pode-se lembrar o trabalho de Arouca (1997) sobre o tema, que tratou de validar um material programado para universitários com vistas ao ensino do texto dissertativo, em alunos do $2^{\circ}$ ano diurno do Curso de Comunicação Social de uma Universidade privada no interior de São Paulo.

Os resultados mostraram que, em relação aos testes de conhecimentos iniciais, os alunos não dominavam o conhecimento das características do texto dissertativo.

A análise dos resultados do Pós-teste permitiu concluir que os sujeitos, embora tivessem aumentado seus conhecimentos teóricos sobre a estrutura e composição do texto dissertativo, não 
possuem a prática e a fluência da escrita. Conclui-se, neste trabalho, que a falta de hábito de leitura é empecilho grande para o processo de compreensão e se reflete na expressão escrita dos sujeitos.

A elaboração do material aplicado, em forma seqüencial, em grau crescente de complexidade, colaborou para a criação dos textos, favorecendo o processo ensino-aprendizagem desses sujeitos e contribuindo relevantemente para a expressão escrita dos mesmos.

A utilização de algumas características do Método Keller, embutidas no material programado, demonstrou aspectos positivos para o ensino-aprendizagem da redação.

Utilizando-se o material durante um tempo maior, para que haja mais prática de produção de textos e com monitores para dedicar atenção mais individualizada para alunos com deficiências mais sérias de expressão, o processo ensino-aprendizagem poderia resultar ainda mais eficiente.

Em suma, por meio deste trabalho, pôde-se perceber que o material programado pode ser útil para a realidade que ora se apresenta nas salas de aula.

\section{Referências}

Barras, R. 1995. Students Must Write. A Guide to Better Writing the Coursework and Examinations. London: Routledge.

Bastos, D. R. 1995. Análise de Discursos Produzidos por Universitários sob Condições Didático Pedagógicas Especificas. Doutorado. São Paulo: USP.

Bright, R. 1993. - Writing Instruction in the Intermediate Grades: What is said, what is done. What is understood. Newark: IRA.

Carone, F.B. 1976. O Desempenho Lingüistico dos Candidatos ao Vestibular: Concordância Verbal. Cadernos de Pesquisa, 19:39-52.

Chacón, C. T. 1989. El plan Keller como Estrategia en El Area de Comprension- Lectora en un Sistema a distancia. Paradigma. 10 (I): 120 Junho/ 89. 106-120.

Duran, A. P. 1981. Padrões de Comunicação Oral e Compreensão da Comunicação Escrita na Universidade: Estudos no Nordeste. Doutorado. São Paulo: IPUSP.

Hudson, S. 1988. Chidren's perceptions of classroom writing: ownership with - in a continuum of control in R. Bright - Writing Instruction in the Intermediate.Grades. Newark: IRA.

Keller, F. S. 1967. Engineering Personalized Instruction in The Classroom. Revista Interamericana de Psicologia. 1 (3): 144-156.

Keller, F. S. 1968. Good Bye Teacher... Journal of Applied Behavior Analysis, 1: 78-79.

Keller, F. S. 1970. Aprendizagem: teoria do reforço. Tradução por R. Azzi, L. Zimmerman, L. O. S. Queiroz, São Paulo: Herder.

Keller, F. S. 1983. Aprendendo a Ensinar: Memórias de um Professor Universitário. São Paulo: Edicom.

Kock, R. A. A. 1997. Eficiência de um Sistema Personalizado de Instrução de Física em curso de Engenharia. Mestrado PUCCAMP. Campinas.

Marini, A. 1980: Remediação da Leitura e Inteligibilidade de Texto: Estudos Contrastivos. Mestrado. São Paulo: IPUSP.

Marini, A. 1986. Compreensão da Leitura no Ensino Superior: Teste de um Programa para Treino de Habilidades. Doutorado. São Paulo: IPUSP.

Pereira, M. E. M. 1983. Uma Análise das Dificuldades de Compreensão de Textos entre Estudantes Universitários. Mestrado. São Paulo: IPUSP.

Rocco, M. T. F. 1981. Crise na Linguagem: A Redação no Vestibular. São Paulo: Mestre Jou.

Santos, A.A. A. 1989. Leitura entre Universitários: Diagnóstico e Remediação. Doutorado. Instituto de Psicologia. São Paulo.

Santos, L. M. 1987. Criatividade e Ensino. in G. P. Wittere J. F. B. Lomônaco. Psicologia da Aprendizagem: Aplicações na Escola. SP: EDUSP.

Sato, N. 1989. O Aluno e a Produção do Texto Escrito: Travessias - Uma análise de redações de alunos do $2^{\circ}$ grau. Mestrado. Faculdade de Educação. USP.

Schiefele, H. 1964. Ensino Programado: Resultados e Problemas teóricos e Práticos. Tradução de Else GrafKalmus. São Paulo: Melhoramentos. 
Unrau, N.J. Ruddell, R.B. 1995. Interpreting text in classroom context.Journal ofLiteracy. 9: 11-17.

Witter, G. P. 1973. Um novo Sistema de Ensino: Curso Programado. In G. P. Witter, J. F B. Lomônaco; M. S. Copit, A. Liberalesso \& E. M. Amarante. A Psicologia e a Aprendizagem em Sala de Aula. Campinas: PUCCAMP.

Witter, G. P. 1975. Ciência, Ensino e Aprendizagem. São Paulo: Alfa - Ômega.

Witter, G. P. \& Rosamilha, N. 1969. Estudos Comparativos de dois Métodos de Ensino. Ciência e Cultura, 21 (2):393-394.

Witter, J. S. \& Witter, G. P. 1973. Um Curso Programado de História. Anais do VI Simpósio Nacional dos Professores Universitários de História. Vol. 11, USP, São Paulo. 